\title{
Extracorporeal Membrane Oxygenation in Critical Care: Past, Present, and Future
}

\author{
Steven A. Conrad ${ }^{1}$ Peter T. Rycus ${ }^{2}$ \\ ${ }^{1}$ Division of Critical Care Medicine, Louisiana State University Health \\ Sciences Center, Shreveport, Louisiana, United States \\ ${ }^{2}$ Extracorporeal Life Support Organization, Ann Arbor, Michigan, \\ United States
}

\begin{abstract}
Address for correspondence Steven A. Conrad, MD, PhD, Division of Critical Care Medicine, LSU Health, 1501 Kings Highway, Shreveport, LA 71103, United States (e-mail: sconrad@Isuhsc.edu).
\end{abstract}

J Card Crit Care TSS 2017;1:60-64

\begin{abstract}
Keywords

- extracorporeal membrane oxygenation

- artificial lung

- acute respiratory failure

- acute cardiac failure

- extracorporeal life support

- extracorporeal pulmonary resuscitation

Extracorporeal membrane oxygenation (ECMO) provides support for cardiac and pulmonary failure, and it was introduced into clinical practice over 40 years ago. The translation of surgical extracorporeal circulation into long-term support was enabled by the development of efficient, biocompatible artificial lungs and blood pumps. Early clinical trials in adult patients did not support clinical benefit in acute respiratory failure, but they were plagued by lack of center experience, older approaches to management, and lack of understanding of ventilator-induced lung injury. Recent clinical trials and retrospective studies, however, suggest a benefit in selected patients. Three neonatal trials for respiratory failure led to ECMO as a standard of care in this population, as well as in the pediatric population despite lack of controlled trials. Cardiac support with ECMO took a foothold in the management of pediatric congenital heart disease in the perioperative period, and subsequently expanded to adult cardiac failure for both perioperative and nonsurgical indications. Presently, ECMO is used to support a variety of etiologies of cardiac and pulmonary failure in all age groups. Expanding indications include support of septic shock, cardiopulmonary arrest, and donation after cardiac death, as well as bridging patients with chronic disease to transplant or long-term support devices. The future is focused on developing integrated support systems, overcoming the requirement for anticoagulation, and perfecting long-term implantable or paracorporeal pulmonary support systems.
\end{abstract}

\section{Introduction}

Extracorporeal membrane oxygenation (ECMO) is a member of a family of extracorporeal support techniques (extracorporeal life support [ECLS]) that provides support of gas exchange and circulation to patients with cardiac and/ or pulmonary failure. Introduced into clinical practice over 40 years ago, ECMO is a prototypical example of translational research to support patients with advanced cardiopulmonary failure. A key component of ECMO is the transport of oxygen into blood across a semipermeable membrane. This phenomenon was first recognized in 1944 when Kolff et al noted that blood became oxygenated as it passed through the cellophane chambers of their artificial kidney. ${ }^{1}$ Modern artificial membrane lungs are capable of providing sufficient transfer of oxygen and carbon dioxide to fully support patients.

ECMO is indicated when the patient has an acute, potentially reversible, life-threatening form of respiratory or cardiac failure that is unresponsive to conventional therapy. It is most commonly used as a bridge to recovery in severe respiratory failure, because no long-term support devices such as implantable artificial lungs are currently available. Its use as a bridge to lung transplantation in irreversible lung disease is a growing indication. When used for cardiac support, it can be used for bridge to recovery, but also as a bridge to long-term support with devices such as ventricular assist devices (VADs), or to transplantation.
DOI https://doi.org/ 10.1055/s-0038-1626673 ISSN 2457-0206.
Copyright @ 2017 Official Publication of The Simulation Society (TSS), accredited by International Society of Cardiovascular Ultrasound (ISCU)
License terms

(ㅇ)(1) $\ominus \circledast$ 


\section{Historical Perspective}

As experience with extracorporeal circulation developed during the 1950s to support cardiac surgery, it was obvious that the life-supporting technique itself became lethal when used for more than a few hours. Thrombocytopenia, coagulopathy, hemolysis, generalized edema, and deterioration of organ function all occurred in proportion to the amount of time on cardiopulmonary bypass. The experiments of Lee et $\mathrm{al}^{2,3}$ Dobell et al, ${ }^{4}$ and others indicated that the direct exposure of blood to oxygen gas was largely responsible for this apparent toxicity. These observations prompted the development of an artificial lung in which a gas-permeable membrane was interposed between the blood and the gas phase. Observation of blood in the Kolff artificial kidney, in which the blood was separated from the environment by a cellophane membrane, indicated that venous blood could become oxygenated if a suitable gas-permeable membrane were developed. ${ }^{1}$ The first successful membrane oxygenator was built by Clowes et al. ${ }^{5}$ They used sheets of polyethylene membrane that had a low but definite permeability to oxygen and carbon dioxide $\left(\mathrm{CO}_{2}\right)$. By using a very large surface area, a device was built, which allowed gas exchange without a direct gas interface, and this hand-made device was used for cardiac surgery in patients in 1956.

The development of dimethylpolysiloxane membranes by Kammermeyer in 1957 was a major advance. ${ }^{6}$ This unique material allows for the transfer of $\mathrm{CO}_{2}$ and oxygen at rates that were more than 10 times greater than those through other plastics. Using this new plastic (also referred to as "silicone rubber"), Kolobow et $\mathrm{al}^{7}{ }^{7}$ Landé et al,, ${ }^{8,9}$ and others constructed blood oxygenators that were quite efficient and successful.

Diffusion limitation of oxygen through boundary layers in the blood phase was a performance barrier in early artificial lungs, and the use of secondary flows to address this problem was studied by Weissman and Mockros, ${ }^{10,11}$ Bartlett and Drinker, ${ }^{12}$ and others. With the collaboration of the medical industry a series of membrane lungs became available for clinical trials and general usage. Kolobow and Zapol, ${ }^{7}$ Bartlett et al, ${ }^{12}$ and others demonstrated that extracorporeal circulation of the blood could be performed for days or weeks without toxicity or hemolysis as long as the direct blood-gas contact was avoided. Beginning with Gibbon, all the studies on extracorporeal circulation have been conducted with the use of heparin anticoagulation at a dose sufficient to produce an infinitely long clotting time. Bartlett et $\mathrm{al}^{12}$ demonstrated that much lower doses of heparin could be used, producing prolonged but measurable clotting time which minimized bleeding complications. Several groups studied the management and physiology of prolonged extracorporeal circulation in a variety of animal models. ${ }^{13-16}$

With these improvements in the equipment and technology of cardiopulmonary bypass, it was possible to characterize physiologic and hematologic responses of the normal animal during prolonged extracorporeal circulation. Several investigators demonstrated that extracorporeal circulation for days was possible without causing significant injury to normal animals. Hemodynamics was easy to regulate. Acidosis, capillary permeability, and organ deterioration that often plagued cardiopulmonary bypass in the operating room did not occur. Bleeding was minimal with adequate control of heparin. Hemolysis was negligible. Thrombocytopenia inevitably occurred but was manageable. All these studies in the animal laboratory showed that the technique was feasible, and they provided the background for early clinical trials.

In 1976, Bartlett and colleagues successfully applied bedside extracorporeal support to treat a newborn with meconium aspiration, marking the beginning of ECMO in critical care. ${ }^{17}$ This was the era in which intensive care units were being introduced, hemodialysis was becoming more widely used, and positive-pressure ventilation was better understood. Infants, children, and adults were surviving cardiopulmonary insults that once were fatal. Acute respiratory distress syndrome (ARDS) emerged as a major problem in the intensive care unit (ICU) population.

\section{Clinical Trials}

Several clinical trials published demonstrating clear survival benefit in infants suffering from severe respiratory failure. ${ }^{18-20}$ Early randomized controlled studies in adults with ARDS demonstrated no such benefit, ${ }^{21,22}$ but smaller studies and case reports emerged with reports of more than $50 \%$ survival in those treated with ECMO, in addition to maximal ventilatory management. ${ }^{23,24}$ In 1989, the Extracorporeal Life Support Organization (ELSO) was formed and the ELSO registry database established.

\section{Current Technology and Patient Management}

Inherent in the use of advanced support technology is the risk of the equipment and the associated patient management. It is likely that the equipment used in the early years of ECMO and the lack of understanding of concepts such as ventilator-induced lung injury contributed to the poorer outcomes than seen today.

Early ECMO was performed with circuits that comprised a high extracorporeal volume, high surface area, and components that were incompatible with blood, resulting in significant complement and platelet activation and systemic inflammation. Vascular access was obtained by surgical cutdown often using thoracotomy tubes, since dedicated vascular cannulae for peripheral access did not exist. Anticoagulation levels were kept high due to the higher thrombogenicity of the circuit, and bleeding complications were profound by today's standards. Blood loss of 1.5 to $1 \mathrm{~L} / \mathrm{d}$ was not uncommon. ${ }^{21}$

Substantial improvement in equipment has ensued over the past 40 years. Vascular access is now typically percutaneous using thin-walled cannulae with antithrombotic coatings. Introduction of the dual-lumen cannula allowing for single-site cannulation has simplified venovenous support for respiratory failure. This approach also permits awaking and mobilizing patients, now increasingly recognized 
as important conditioning steps to recovery. Bleeding from access sites is now distinctly uncommon, and the need for blood transfusions has dropped considerably. Some patients may be managed without blood transfusion. The original metal Bramson artificial lung was replaced by the solid silicone lung (with no air-blood interface), which dominated the field until recent years. Current oxygenators are constructed of hollow fibers with low-resistance, high-efficiency, and low priming volume. The new generation of centrifugal blood pumps have low priming volume, low risk of hemolysis, and can run for weeks without need for replacement. Antithrombotic coatings reduce the level of systemic anticoagulation and greatly reduce bleeding complications.

Clinicians now have a better understanding of managing the failing heart and injured lungs, leading to a greater chance of recoverability. The concepts of protective lung ventilation were not introduced until after the $\mathrm{NIH}^{21}$ and Morris $^{22}$ trials. Patients in these trials were subjected to injurious levels of ventilator support. These protective concepts were developed by the time of the CESAR (Conventional ventilatory support versus Extracorporeal membrane oxygenation for Severe Adult Respiratory failure) trial, and they likely played a part in the improved outcome.

\section{Applications}

Present-day applications of ECMO include the traditional uses for support of cardiac and respiratory failure. Cardiac ECMO is used in the neonatal and pediatric populations for several indications, including postoperative congenital heart support and acute myocarditis. In the adult population, it is rapidly becoming the preferred acute short-term therapy for postcardiotomy syndrome as well as acute myocarditis as a bridge to recovery or to decision. VADs are now being reserved for bridge to transplant or destination, although some patients recover enough function during support to have their VAD explanted.

Support of respiratory failure remains the most common indication for ECMO. Historically it was used for patients with acute reversible respiratory failure with expected recovery, and this still remains its most common application. With recent improvements in technology, in particular with dual-lumen single cannulation of the internal jugular vein, patients are being supported to transplant. With current management, patients can participate in physical rehabilitation, including ambulation, thereby improving their ability to successfully undergo transplantation.

\section{Extracorporeal Cardiopulmonary Resuscitation}

Extracorporeal cardiopulmonary resuscitation (ECPR) entails the rapid deployment of femoral venoarterial ECMO in patients not responding to conventional CPR. ECPR is one of the most rapidly growing segments of ECLS as reported to the ELSO registry. In the interval of 2012-2015, 869 neonatal, 1,106 pediatric, and 1,337 adult cases were reported. This number under-represents the actual number, as several centers performing ECPR are not reporting data to the ELSO registry. ${ }^{25}$ Rapid deployment is facilitated by recent technological improvements, including hollow fiber oxygenators with centrifugal pumps, which can be rapidly primed with crystalloid solutions. Results for in-hospital cardiac arrest are encouraging, whereas its use in out-of-hospital arrest, traditionally associated with poor outcomes, shows potential. ${ }^{26}$ The challenge in the latter may be in selection of patients and activating the full chain of survival from EMS to interventional cardiology, as in-hospital arrest is usually witnessed, whereas out-of-hospital often is not.

\section{Present Day}

Early adoption as a widely accepted support modality occurred in severe neonatal respiratory failure following the publication of prospective clinical trials ${ }^{18-20}$ and in pediatric cardiac failure, particularly in the perioperative environment. ${ }^{27,28}$ It subsequently became increasingly adopted in pediatric respiratory failure ${ }^{29}$ and adult cardiac support with apparent success but without prospective studies. Use in adults for respiratory failure was not widely adopted until recently, following publication of the CESAR trial ${ }^{30}$ and reports from the H1N1 epidemic suggesting a survival benefit. ${ }^{31,32}$ Currently, the most rapidly growing applications of ECMO is to provide circulatory support to patients in cardiac arrest (ECPR) ${ }^{33}$ and short-term circulatory support.

The ELSO maintains a registry of ECLS cases reported by its members of health care organizations, which currently number more than 300 and represent a global cross section of ECLS ( $\boldsymbol{- T a b l e ~} \mathbf{1}$ ). The number of actual cases worldwide is likely much higher as the ELSO participation is voluntary, and the registry does not capture all cases performed.

\section{Future of Extracorporeal Membrane Oxygenation}

The driving force for the future of ECMO will likely be improvements in technology. Miniaturization and automation of support systems will move ECMO from an extraordinary therapy to the current status enjoyed by continuous renal replacement therapy, with nurse-driven bedside management. A large step in this direction has been realized in the commercial production of small integrated systems (CardioHelp, Maquet). Newer technology will need to address mobility of patients and even permit excursions outside of the hospital (a feat that has already been accomplished). Future systems and changes in practice paradigms will allow for use of ECMO as a replacement for mechanical ventilation. Some ECMO centers actively pursue extubation of patients on ECMO, removing a source of further injury and infection. It is not inconceivable that ECMO could be first-line therapy in selected patients, avoiding intubation altogether. This is particularly true for hypercapnic respiratory failure, such as chronic obstructive pulmonary disease (COPD) exacerbation, for which dedicated $\mathrm{CO}_{2}$ removal systems are currently hitting the market. 
Table 1 ELSO International Summary, July 2017

\begin{tabular}{|c|c|c|c|c|c|}
\hline & Total runs & \multicolumn{2}{|c|}{ Survived ECLS } & \multicolumn{2}{|c|}{ Survived to discharge } \\
\hline \multicolumn{6}{|l|}{ Neonatal } \\
\hline Pulmonary & 26,719 & 22,394 & $83 \%$ & 19,252 & $72 \%$ \\
\hline Cardiac & 7,266 & 4,727 & $65 \%$ & 2,987 & $41 \%$ \\
\hline ECPR & 1,613 & 1,089 & $67 \%$ & 666 & $41 \%$ \\
\hline \multicolumn{6}{|l|}{ Pediatric } \\
\hline Pulmonary & 8,287 & 5,608 & $67 \%$ & 4,812 & $58 \%$ \\
\hline Cardiac & 9,593 & 6,620 & $69 \%$ & 4,941 & $51 \%$ \\
\hline ECPR & 3,615 & 2,078 & $57 \%$ & 1,508 & $41 \%$ \\
\hline \multicolumn{6}{|l|}{ Adult } \\
\hline Pulmonary & 13,712 & 9,174 & $66 \%$ & 8,040 & $58 \%$ \\
\hline Cardiac & 12,566 & 7,181 & $57 \%$ & 5,222 & $41 \%$ \\
\hline ECPR & 3,995 & 1,572 & $39 \%$ & 1,144 & $28 \%$ \\
\hline Total & 87,366 & 60,443 & $69 \%$ & 48,572 & $55 \%$ \\
\hline
\end{tabular}

Abbreviations: ECLS, extracorporeal life support; ECPR, extracorporeal cardiopulmonary resuscitation; ELSO, Extracorporeal Life Support Organization.

The greatest hurdle remaining is perhaps anticoagulation. Today's antithrombotic coatings can reduce heparin requirements but not eliminate its use, requiring the use of complex monitoring and anticoagulation management. Advanced circuit coatings have the potential to eliminate this restriction altogether. Promising coatings such as nitric oxide-releasing coatings are currently under development and show promise in preclinical studies.

Another exciting extension of ECMO is the artificial implantable lung for destination therapy of chronic heart failure. In this capacity, blood would be pumped by the right ventricle, eliminating the need and problems of a blood pump. Animal experiments clearly demonstrated the feasibility, yet work remains on optimal hemodynamic configuration, oxygenator design, and antithrombotic coatings. With continued development, these advances should be realizable in the not-too-distant future.

\section{Conclusion}

Currently, ECMO is used for severe heart and lung failure in all ages, primarily in reversible disease but expanding to bridging to long-term support devices or transplantation. Research is focused on improving anticoagulation and devices, defining indications, and exploring new applications such as septic shock, ECPR for cardiac arrest, and extracorporeal support for donation after cardiac death (DCD) to salvage organs for transplantation. Laboratory research has continued as clinical practice proceeded, and it currently includes an artificial placenta for very premature infants ${ }^{34}$ and four versions of implantable, wearable lungs for chronic support.

\section{References}

1 Kolff WJ, Berk HTJ, Welle NM, van der Ley AJW, van Dijk EC, van Noordwijk J. The artificial kidney: a dialyser with a great area. Acta Med Scand 1944;117(2):121-134

2 Lee WH Jr, Krumhaar D, Derry G, et al. Comparison of the effects of membrane and non-membrane oxygenators on the biochemical and biophysical characteristics of blood. Surg Forum 1961;12:200-202

3 Lee WH Jr, Krumhaar D, Fonkalsrud EW, Schjeide OA, Maloney JV Jr. Denaturation of plasma proteins as a cause of morbidity and death after intracardiac operations. Surgery 1961;50:29-39

4 Dobell AR, Galva R, Sarkozy E, Murphy DR. Biologic evaluation of blood after prolonged recirculation through film and membrane oxygenators. Ann Surg 1965;161:617-622

5 Clowes GH Jr, Neville WE. An artificial lung dependent upon diffusion of oxygen and carbon dioxide through plastic membranes. J Thorac Surg 1956;32(5):630-637

6 Kammermeyer K. Silicone rubber as a selective barrier. Ind Eng Chem 1956;49:1685

7 Kolobow T, Spragg RG, Pierce JE, Zapol WM. Extended term (to 16 days) partial extracorporeal blood gas exchange with the spiral membrane lung in unanesthetized lambs. Trans Am Soc Artif Intern Organs 1971;17:350-354

8 Landé AJ, Edwards L, Bloch JH, et al. Clinical experience with a membrane pump-oxygenator. Ann Thorac Surg 1970; 10(5):409-423

9 Landé AJ, Edwards L, Carlson RG, et al. Prolonged near-total bypass with membrane pump-oxygenator. N Y State J Med 1970;70(15):1963-1964

10 Weissman MH, Mockros LF. Oxygen and carbon dioxide transfer in membrane oxygenators. Med Biol Eng 1969;7(2):169-184

11 Weissman MH. Diffusion in membrane-limited blood oxygenators. AIChE J 1969;15(4):627-630

12 Bartlett RH, Isherwood J, Moss RA, Olszewski WL, Polet H, Drinker PA. A toroidal flow membrane oxygenator: four day partial bypass in dogs. Surg Forum 1969;20:152-153 
13 Frederiksen T, Rosen J, Rygg IH, Christensen E, Therkelsen F. Prolonged extracorporeal circulation. Thorax 1963; 18(2):158-161

14 Eberhart RC, Lamy M, Dietrich HP, Ratliff JL, Fallat RJ, Hill JD. Hemodynamic aspects of prolonged extracorporeal oxygenation. Trans Am Soc Artif Intern Organs 1974;20 B:491-497

15 Hill JD, Bramson ML, Hackel A, et al. Laboratory and clinical studies during prolonged partial extracorporeal circulation using the Bramson membrane lung. Circulation 1968;37 (4, Suppl):II139-II145

16 Hill JD, de Leval MR, Mielke CH Jr, Bramson ML, Gerbode F. Clinical prolonged extracorporeal circulation for respiratory insufficiency: hematological effects. Trans Am Soc Artif Intern Organs 1972;18(0):546-552, 561

17 Bartlett RH. Esperanza: the first neonatal ECMO patient. ASAIO J 2017;63(6):832-843

18 Bartlett RH, Roloff DW, Cornell RG, Andrews AF, Dillon PW, Zwischenberger JB. Extracorporeal circulation in neonatal respiratory failure: a prospective randomized study. Pediatrics 1985; 76(4):479-487

19 O'Rourke PP, Crone RK, Vacanti JP, et al. Extracorporeal membrane oxygenation and conventional medical therapy in neonates with persistent pulmonary hypertension of the newborn: a prospective randomized study. Pediatrics 1989;84(6):957-963

20 UK Collaborative ECMO Trail Group. UK collaborative randomised trial of neonatal extracorporeal membrane oxygenation. Lancet 1996;348(9020):75-82

21 Zapol WM, Snider MT, Hill JD, et al. Extracorporeal membrane oxygenation in severe acute respiratory failure. A randomized prospective study. JAMA 1979;242(20):2193-2196

22 Morris AH, Wallace CJ, Menlove RL, et al. Randomized clinical trial of pressure-controlled inverse ratio ventilation and extracorporeal $\mathrm{CO} 2$ removal for adult respiratory distress syndrome. Am J Respir Crit Care Med 1994;149(2 Pt 1):295-305

23 Bartlett RH, Roloff DW, Custer JR, Younger JG, Hirschl RB. Extracorporeal life support: the University of Michigan experience. JAMA 2000;283(7):904-908

24 Pranikoff T, Hirschl RB, Remenapp R, Swaniker F, Bartlett RH. Venovenous extracorporeal life support via percutaneous cannulation in 94 patients. Chest 1999;115(3):818-822
25 Philipp A, Arlt M, Amann M, et al. First experience with the ultra compact mobile extracorporeal membrane oxygenation system CardioHelp in interhospital transport. Interact Cardiovasc Thorac Surg 2011;12(6):978-981

26 Yannopoulos D, Bartos JA, Martin C, et al. resuscitation consortium's advanced perfusion and reperfusion cardiac life support strategy for out-of-hospital refractory ventricular fibrillation. J Am Heart Assoc 2016;5(6):e003732

27 O'Rourke PP, Crone RK. Pediatric applications of extracorporeal membrane oxygenation. J Pediatr 1990;116(3):393-394

28 Meliones JN, Custer JR, Snedecor S, Moler FW, O'Rourke PP, Delius RE. Extracorporeal life support for cardiac assist in pediatric patients. Review of ELSO Registry data. Circulation 1991;84(5, Suppl):III168-III172

29 O'Rourke PP, Stolar CJ, Zwischenberger JB, Snedecor SM, Bartlett RH. Extracorporeal membrane oxygenation: support for overwhelming pulmonary failure in the pediatric population. Collective experience from the extracorporeal life support organization. J Pediatr Surg 1993;28(4):523-528, discussion 528-529

30 Peek GJ, Mugford M, Tiruvoipati R, et al; CESAR trial collaboration. Efficacy and economic assessment of conventional ventilatory support versus extracorporeal membrane oxygenation for severe adult respiratory failure (CESAR): a multicentre randomised controlled trial. Lancet 2009;374 (9698):1351-1363

31 Davies A, Jones D, Bailey M, et al; Australia and New Zealand Extracorporeal Membrane Oxygenation (ANZ ECMO) Influenza Investigators. Extracorporeal membrane oxygenation for 2009 influenza $\mathrm{A}(\mathrm{H} 1 \mathrm{~N} 1)$ acute respiratory distress syndrome. JAMA 2009;302(17):1888-1895

32 Noah MA, Peek GJ, Finney SJ, et al. Referral to an extracorporeal membrane oxygenation center and mortality among patients with severe 2009 influenza A(H1N1). JAMA 2011;306(15):1659-1668

33 Conrad SA, Rycus PT. Extracorporeal membrane oxygenation for refractory cardiac arrest. Ann Card Anaesth 2017;20 (Suppl):S4-S10

34 Partridge EA, Davey MG, Hornick MA, et al. An extra-uterine system to physiologically support the extreme premature lamb. Nat Commun 2017;8:15112 